\title{
Optimasi Perencanaan Produksi Dengan Menggunakan Model Sistem Dinamik Di PT X
}

\author{
E. A. Rachma
}

\begin{abstract}
Abstrak - Pada saat ini, dunia perindustrian telah tumbuh dan berkembang dengan sangat pesat. Meningkatnya jumlah permintaan di pasar dan bertambahnya jumlah pesaing industri di dunia menyebabkan perusahaan harus berlomba - lomba untuk menjadi unggul agar dapat dikenal dan diketahui oleh pasar luas. Salah satunya adalah memperbaiki kelangsungan produksi agar dapat memenuhi permintaan konsumen dengan tepat waktu dan biaya produksi seefisien mungkin. Pada penelitian ini, ditemukan masalah dalam perencanaan produksi yaitu berfluktuasinya permintaan akan produk 3 side seal dan pillow seal sehingga rencana produksi yang diterapkan sebelumnya di PT X sering mengalami kekurangan atau kelebihan dalam memproduksi produk sehingga mengakibatkan biaya produksi yang kurang efisien. Pada penelitian kali ini, pemecahan masalah dilakukan dengan menggunakan sistem program dinamis. Sistem dinamik merupakan teknik matematis yang digunakanuntukpengambilankeputusan yang terdiri dari banyak tahap (multistage). Program dinamis membagi masalah asli dengan sub-sub masalah. Kelebihan metode program dinamik dibandingan dengan metode optimasi lainnya adalah memiliki lebih dari satu rangkaian keputusan. Pada periode agustus 2018 sampai dengan juli 2019 perusahaan dapat menggunakan persediaan dengan beberapa keputusan diantaranya 0, 6598, 9897, dan 13196. Dengan demikian peusahaan yang menggunakan variabel keputusan tersebut mendapatkan biaya produksi sebesar Rp 149.425.025.077 sedangkan jika menggunakan perencanaan produksi aktual perusahaan mendapatkan biaya produksi sebesar Rp 187.489.966.259 dapat disimpulkan jika perusahaan menggunakan program dinamis dapat menghemat sebesar Rp 38.064.941.182 atau setara dengan $20 \%$. Sehingga pada penelitian kali ini dapat diketahui optimasi kapasitas produksi yang dapat digunakan perusahaan sesuai dengan keadaan perusahaan tersebut.
\end{abstract}

Kata Kunci- Perencanaan Produksi, Optimasi Kapasitas Produksi, Program Dinamik

Abstract - At present, the world of industry has grown and developed very rapidly. The increasing number of requests in the market and the increasing number of industrial competitors in the world causes companies to be competing to be superior in order to be known and known by the broad market. One of them is to improve the continuity of production so that it can meet consumer demand in a timely manner and production costs as efficiently as possible. In this study, problems were found in production planning so researchers wanted to conduct research using a dynamic program system. Dynamic system is a mathematical technique used for multi-stage decision making. The program dynamically divides the original problem with sub-problems. The advantage of dynamic program methods compared to other optimization methods is to have more than one set of decisions. In the August 2018 to July 2019 period companies can use inventory with several decisions including 0, 6598, 9897, and 13196. Thus companies that use the decision variable get a production cost of Rp 149,425,025,077 while if using the actual production planning the company gets a fee production of Rp. 187,489,966,259 can be concluded if the company uses a dynamic program can save Rp. 38,064,941,182, equivalent to 20\%. So that this research can be known optimization of production capacity that can be used by the company in accordance with the state of the company.

Keywords_-Production Planning, Production Capacity Optimization, Dynamic Program

\section{PENDAHULUAN}

Dunia perindustrian persaingan bisnis semakin ketat dan sulit, bertambahnya perusahaan yang lebih unggul menjadi masalah utama dalam membangun sebuah bisnis. Kondisi ini menyebabkan banyak perusahaan yang berlomba-lomba menjadi yang terbaik dibidangnya. Dengan meningkatnya persaingan, tentunya perusahaan akan lebih meningkatkan kualitas manajemennya agar dapat tetap bertahan dalam persaingan. Salah satunya adalah memperbaiki kelangsungan produksi agar dapat memenuhi permintaan konsumen dengan tepat waktu dan biaya produksi seefisien mungkin. Oleh

Eine Aisyah Rachma, Mahasiswa Teknik Industri, Universitas Indraprasta PGRI, Jakarta. (eineaisyah@gmail.com,) karena itu perusahaan di tuntut bekerja secara efektif dalam menghasilkan ouput dan efisien dalam menggunakan input dengan kapasitas produksi perusahaan. Produksi adalah fungsi pokok dalam setiap organisasi industri yang mencangkup aktivitas guna penciptaan nilai tambah produk yang merupakan output dari setiap organisasi tersebut. Dalam proses produksi, terdapat elemen - elemen yang membentuk kesatuan yang saling berinteraksi membentuk sistem, dan disebut sistem produksi. Sistem produksi memiliki komponen-komponen atau elemen struktural dan fungsional yang berperan penting menunjang kontinusitas oprasional sistem [1]. Perencanaan produksi pada dasarnya adalah usaha perusahaan untuk mengatasi fluktuasi demand 
(permintaan). Perencanaan jumlah produksi yang optimal, diharapkan pihak perusahaan akan menghasilkan jumlah produksinya sesuai dengan besarnya kebutuhan dan permintaan konsumen. Setiap perusahaan, terdapat berbagai keterbatasan dan masalah-masalah yang harus dihadapi. Salah satunya yaitu menentukan perencanaan produksi yang optimal. Hal ini merupakan suatu kendala yang harus diatasi oleh pihak perusahaan agar kelancaran produksi tetap terjaga, maka dengan adanya berbagai kendala berupa masalah tersebut, mengharuskan pihak manajemen menyusun suatu perencanaan produksi yang optimal agar didapat jumlah produksi yang menguntungkan perusahaan. [3] Program dinamik adalah Salah satu teknik matematika yang digunakan untuk mengoptimalkan proses pengambilan keputusan secara bertahap ganda. Suatu masalah pengambilan keputusan yang multistage dipisah pisahkan menjadi suatu sub masalah yang berurutan dan saling berhubungan. Program dinamik terbagi menjadi dua yaitu secara deterministik dan probabilistik [7]. Metode program dinamis juga dapat digunakan dengan mempertimbangkan batasan kapasitas gudang akan memberikan total biaya yang minimal [6].

PT $X$ adalah salah satu perusahaan yang bergerak di bidang produksi kemasan obat dan makanan yang memiliki 5 jenis produk yanng diproduksi, diantaranya Roll, Standing Pouch, Gusset, Pillow Seal, dan 3 Side Seal. Perusahaan menerapkan sistem make to order yaitu strategy yang dapat mengurangi masalah persediaan berlebihan yang umum dengan make traditional strategy untuk persediaan. Masalah yang dihadapi perusahaan adalah permintaan produksi mengalami fluktuasi pada setiap periode. Fluktuasi ini disebabkan karna permintaan konsumen terhadap produk yang selalu berubah dipasar luas, masalah yang disebabkan fluktuasinya permintaan produk membuat perusahaan sering mengalami kelebihan atau kekurangan dalam perencanaan produksi seingga mengakibatkanb biaya produksi yang dikeluarkan perusahaan belum efisien. Permasalahan ini menyebabkan perusahaan sering kali tidak dapat memperkirakan jumlah produksi yang tepat dalam menentukan pasar. Berikut dibawah ini adalah grafik produksi pada produk pillow seal dan 3 sead seal pada periode Agustus 2017 - Juli 2018.

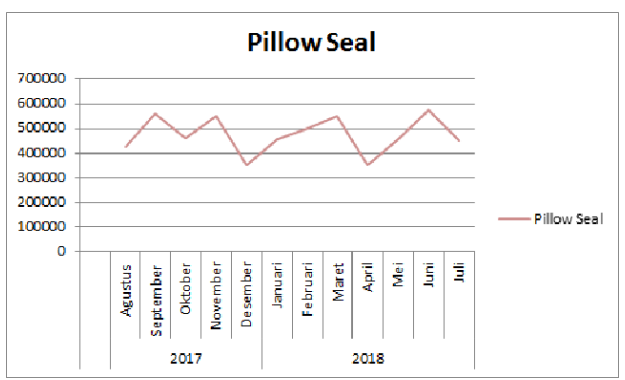

Gambar 1. Permintaan produk pillow seal

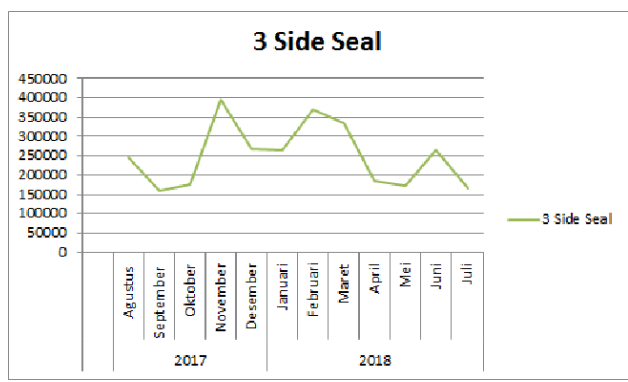

Gambar 2. Permintaan produk 3 sead seal

Berdasarkan gambar 1 dan gambar 2 memperlihatkan jumlah permintaan pada produk pillow seal dan 3 side seal setiap bulannya pada periode agustus 2018 - juli 2019 yang mengalami fluktuasi. Produk pillow seal dan 3 sead seal merupakan produk unggulan di PT X karena produsen makanan dan obat-obatan yang menjadi konsumen utama PT X menjadikan produk pillow seal dan 3 sead seal menjadi kemasan utamanya. Dengan mengetahui kondisi tersebut maka perusahaan perlu melakukan perencanaan produksi sebagai suatu perencanaan yang strategis yang bertujuan untuk memberikan keputusan berdasarkan sumber daya yang dimiliki perusahaan dalam memenuhi permintaan akan produk yang dihasilkan, dan biaya produksi yang dikeluarkan dapat diminimumkan. Kondisi tersebut dapat dicapai dengan menggunakan metode program dinamik. Oleh karena itu, penelitian ini penting untuk dilakukan pada perencanaan produksi pillow seal dan 3 side seal di PT. X dengan harapan hasil dari penelitian ini dapat digunakan sebagai bahan pertimbangan atau alternatif dalam mencapai produksi yang optimal. Penelitian ini bertujuan untuk melakukan perencanaan produksi pada periode selanjutnya yaitu periode Agustus 2018 sampai dengan Juli 2019.

Penelitian - penelitian mengenai penerapan metode program dinamik dalam perencanaan produksi memberikan hasil yang lebih baik dibandingkan dengan sistem yang diterapkan perusahaan. Terbukti dari penghematan yang diperoleh dengan metode ini menghasilkan penghematan biaya produksi sebesar 
Rp 9.969.071.399 pada fractination and ferinery factory (FRF) di PT. XYZ [2].

\section{METODE PENELITIAN}

Adapun metode penelitian yang akan digunakan dalam penelitian ini adalah metode perencanaan produksi dengan menggunakan metode dinamis. Metode ini digunakan untuk mengetauhi keputusan yang dapat digunakan sesuai dengan keadaan perusahaan. Data yang akan digunakan adalah data permintaan, data produksi, biaya TK regular, biaya TK overtime, biaya produksi,biaya listrik, dan biaya simpan serta data kapasitas gudang PT X. Jenis masukan (inputs) yang dipergunakan dalam rencana produksi dengan menggunakan sistem dinamis adalah data permintaan, data produksi, biaya TK regular, biaya TK overtime, biaya produksi,biaya listrik, dan biaya simpan serta data kapasitas gudang. Sedangkan yang menjadi keluaran (outputs) adalah hasil rencana produksinya.

Penelitian ini dilakukan di PT X yang terletak di Jawa Barat Indonesia. Penelitian dilakukan pada bulan Agustus 2018. Dalam proses penelitian ini data yang diambil adalah data permintaan pada periode tahun 2017-2018. Data lain yang diambil adalah biayabiaya produksi, biaya penyimpanan tahun 2017-2018. Adapun langkah-langkah dalam proses pengerjaan penelitian ini adalah sebagai berikut [2]:

1. Mengidentifikasi variabel masukan

Variabel masukan dalam satu periode dalam model ini adalah $\mathrm{Sn}=$ jumlah permintaan tiap periode, biaya variabel produksi, dan biaya simpan, jumlah persediaan dari periode i yang dibawa keperiode $\mathrm{i}+1$

2. Mengidentifikasi variabel keputusan (Xn)

Variabel keputusan yang digunakan adalah menentukan jumlah produk yang akan diproduksi setiap periode (stage) untuk $\mathrm{i}=1,2,3, . . \mathrm{n}$

3. Mengidentifikasi kendala-kendala perusahaan (kapasitas gudang, kapasitas produksi, jumlah persediaan maksimum yang diizinkan)

S.t. $\mathrm{S}_{\mathrm{n}}-\mathrm{i}<\mathrm{xn}_{\mathrm{n}}<\mathrm{S}_{\mathrm{i}}$

4. Merumuskan persamaan fungsi tujuan :

$f_{n} *(\mathrm{i})=\min \left[f_{n}\left(X_{n}, I_{n}+X_{n}-S_{n}\right)+f^{*} n-1\left(I_{n}+X_{n}-S_{n}\right)\right]$

5. Penyelesaian model dengan program dinamik, yaitu :

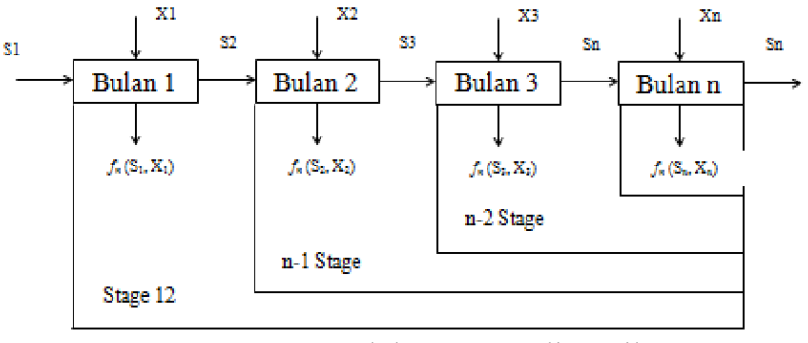

Gambar 3. model program dinamik

\section{Keterangan:}

a. Sn (Stage) : input ketahap selanjutnya (Sn-1), diantaranya: permintaan tiap periode, biaya variabel dan biaya simpan

b. Stage $\mathrm{n}$ : bulan ke $\mathrm{n}$

c. Xn : keputusan ke tahap selanjutnya $(\mathrm{Xn}-1)=$ tingkat produksi setiap periode

d. Fungsi rekursif : minimasi total biaya produksi $f_{n}(\mathrm{~S} 1, \mathrm{Xi})$

6. Analisis pemecahan masalah

Setelah dilakukan perhitungan dan penentuan jumlah produksi serta jumlah persediaan yang optimal menggunakan metode program dinamik maka langkahnya yaitu melakukan analisa pemecahan masalah. Analisa dilakukan untuk melihat berapa jumlah produksi optimum yang harus diproduksi dengan memperhatikan jumlah persediaan, penentuan jadwal produksi dengan menggunakan metode program dinamik akan dapat meminimasi biaya.

Penelitian dimulai dengan mengidentifikasi masalah yang terdapat di lapangan dengan mengumpulkan data survay berdasarkan literatur, buku, jurnal, skripsi, dan penelitian yang relavan. Pengumpulan data mengenai biaya produksi, biaya listrik, permintaan produksi pada periode sebelumnya, kapsitas produksi, jumlah tenaga kerja, biaya tenaga kerja, jam kerja karyawan, pengaturan kerja berdasarkan kebijakan perusahaan. Kemudian diolah menggunakan metode program dinamis dan selanjutnya dianalisis dan disimpulkan hasil dari penelitian.

Untuk melaksanakan fungsi-fungsi produksi dengan baik, maka diperlukan rangkaian kegiatan yang akan membentuk suatu system produksi, system produksi merupakan kumpulan dari sub sistem-sub sistem yang saling berinteraksi dengan tujuan mentransformasi input produksi menjadi output produksi. Input produksi ini dapat berupa bahan baku, mesin, tenaga kerja, modal dan informasi, sedangkan output produksi merupakan produk yang dihasilkan berikut hasil sampingnya seperti limbah, informasi dan 
sebagainya. Sub sistem-sub sistem dari sistem produksi tersebut antara lain adalah perencanaan dan pengendalian produksi, pengendalian kualitas, penentuan standar-standar operasi, penentuan fasilitas produksi, perawatan fasilitas produksi, dan penentuan harga pokok produksi. sub sistem-sub sistem dari sistem produksi tersebut akan membentuk konfigurasi system produksi. Keandalan dari konfigurasi sistem produksi ini akan tergantung dari produk yang dibuat serta bagaimana cara membuatnya (proses produksinya). Cara membuat produk tersebut dapat berupa "jenis" proses produksi menurut cara menghasilkan output, "operasi" dari pembuatan produk, dan "variasi" produk yang dihasilkan [9].

Perencanaan produksi akan mudah dibuat bila tingkat permintaan bersifat konstan atau bila waktu produksi tidak menjadi kendala. Tetapi kedua kondisi ini jarang terjadi dalam keadaan sebenarnya, dimana secara nyata tingkat permintaan akan berfluktuasi dan perusahaan selalu dibatasi oleh tanggal waktu penyerahan. Perencanaan yang tidak tepat dapat mengakibatkan tinggi/rendahnya tingkat persediaan, sehingga mengakibatkan peningkatan ongkos simpan/ongkos kehabisan persediaan. Dan yang lebih fatal, hal tersebut dapat mengurangi pelayanan kepada konsumen karena keterlambatan penyerahan produk [4].

Perencanaan produksi pada dasarnya adalah usaha perusahaan untuk mengatasi fluktuasi demand (permintaan). Perencanaan jumlah produksi yang optimal, diharapkan pihak perusahaan akan menghasilkan jumlah produksinya sesuai dengan besarnya kebutuhan dan permintaan konsumen. Setiap perusahaan, terdapat berbagai keterbatasan dan masalah-masalah yang harus dihadapi. Salah satunya yaitu menentukan perencanaan produksi yang optimal. Hal inimerupakan suatu kendala yang harus diatasi oleh pihak perusahaan agar kelancaran produksi tetap terjaga, maka dengan adanya berbagai kendala berupa masalah tersebut, mengharuskan pihak manajemen menyusun suatu perencanaan produksi yang optimal agar didapat jumlah produksi yang menguntungkan perusahaan. [3]

Program dinamik adalah Salah satu teknik matematika yang digunakan untuk mengoptimalkan proses pengambilan keputusan secara bertahap ganda. Suatu masalah pengambilan keputusan yang multistage dipisah pisahkan menjadi suatu sub masalah yang berurutan dan saling berhubungan. Program dinamik terbagi menjadi dua yaitu secara deterministik dan probabilistik [7]. Pada masalah program dinamik deterministik, state yang berada pada tahapan berikutnya ditentukan seluruhnya berdasarkan state dan kebijakan keputusan pada tahapan sebelumnya.

Sedangkan pemrograman dinamik probabilistik, terdapat suatu probabilitas keadaan mendatang yang distribusi peluang ini tetap ditentukan oleh keadaan dan keputusan kebijakan pada keadaan sebelumnya. Sebuah objek disebut berulang (rekursif, recursive) jika setiap objek mengandung dirinya sendiri atau didefinisikan dengan dirinya sendiri [8]. Dalam matematika, defenisi rekursif sebuah fungsi adalah defenisi fungsi yang menggunakan fungsi tersebut. Berikut adalah karakteristik pemprograman dinamik, yaitu berdasarkan proses yang terjadi maka karakteristk pemprograman dinamik dapat dirumuskan sebagai berikut [4]:

1. Masalah dapat dibagi menjadi tahap-tahap.

2. Setiap tahap terdiri dari sejumlah keadaan yang terkait dengannya.

3. Keputusan pada tiap tahap mengubah keadaan yang sedang berlangsung menjadi keadaan yang berhubungan dengan tahap berikutnya.

4. Berpangkal dari keadaan yang sedang berlangsung, keputusan pada tahap berikutnya tidak trgantung pada keputusan yang telah diambil pada tahap sebelumnya.

5. Untuk menentukan keputusan optimal sebuah persamaan rekrusif di formulasikan.

6. Menggunakan persamaan rekrusif, prosedur perhitungan berjalan tahap demi tahap sampai keseluruhan tahap dijalani

Ada dua macam prosedur rekursif yaitu forward recursive equation (perhitungan dari depan ke belakang) dan backward recursive equation (perhitungan dari belakang ke depan) [5].

\section{HASIL DAN PEMBAHASAN}

Permintaan pada produk 3 sead seal dan pillow seal pada Agustus 2017 sampai dengan Juli 2018 dapat dilihat pada Tabel 1 .

Tabel 1 memperihatkan jumlah permintaan produk setiap bulanna selama periode tersebut. Pengolahan data meliputi perhitungan upah tenaga kerja, perhitungan total biaya produksi, biaya simpan kemudian menentukan produksi yang optimal dengan menggunakan program dinamik. 
Tabel 1. Permintaan Produk 3 sead seal dan Pillow seal

\begin{tabular}{ccc}
\hline Tahun & Bulan & $\begin{array}{c}\text { Permintaan produk 3 } \\
\text { sead seal dan pillow } \\
\text { seal }\end{array}$ \\
\hline \multirow{5}{*}{} & Agustus & 671377 \\
& September & 720609 \\
& Oktober & 635547 \\
& November & 945190 \\
& Desember & 621880 \\
& Januari & 721774 \\
$\infty$ & Februari & 873301 \\
\hline & Maret & 887107 \\
& April & 535943 \\
& Mei & 629452 \\
& Juni & 839720 \\
& Juli & 618100 \\
\hline
\end{tabular}

1. Perhitungan upah tenaga kerja

Dari wawancara yang dilakukan oleh manajemen pabrik, perusahaan ini memiiki jumlah diberlakukan adalah $8 \mathrm{jam} / \mathrm{shift}$ dan perusahaan memiliki 3 shift perharinya. Perusahaan bisa menambahkan jam kerja dengan biaya yang teah dipaparkan pada tabel berikut:

a. Jika produksi hanya menggunakan reguler time, maka yang dihasilkan :

Tabel 2. Biaya Tenaga pada Regular Time

\begin{tabular}{lccc}
\hline \multicolumn{1}{c}{ Keterangan } & Jumlah & Satuan \\
\hline Jam/Shift & & 8 & Jam \\
Jumlah Karyawan & & 135 & Shift \\
Jumlah Produksi & & 9000 & $\mathrm{~m} / \mathrm{shift}$ \\
Biaya TK & Rp. & 149.160 & Shift \\
Biaya TK Keseluruhan & Rp. & 20.136 .600 & /Shift \\
Biaya Produksi & Rp. & 2.237 & m/shift \\
\hline
\end{tabular}

b. Apabila perusahaan menambah dengan overtime, maka biaya yang dihasilkan :

Tabel 3. Biaya Tenaga Kerja Overtime

\begin{tabular}{|c|c|c|c|}
\hline Keterangan & \multicolumn{2}{|c|}{ Jumlah } & Satuan \\
\hline Jumlah Karyawan & \multicolumn{2}{|r|}{135} & Shift \\
\hline Jumlah Produksi & \multicolumn{2}{|r|}{375} & Jam \\
\hline Biaya TK OT & $\mathrm{Rp}$ & 18.645 & $/ \mathrm{Jam}$ \\
\hline Biaya TK OT Keseluruhan & $\mathrm{Rp}$ & 2.517 .075 & / Shift \\
\hline Biaya Produksi & $\mathrm{Rp}$ & 6.712 & $\mathrm{~m} / \mathrm{shift}$ \\
\hline Biaya TK pada OT & $\mathrm{Rp}$ & 20.136 & \\
\hline Biaya TK pada RT & $\mathrm{Rp}$ & 6.711 & \\
\hline Selisih TK dengan RT & $\mathrm{Rp}$ & 13.425 & \\
\hline
\end{tabular}

2. Perhitungan biaya produksi dengan biaya simpan

Perhitungan biaya produksi didapatkan dengan menambah jumlah biaya bahan baku yang digunakan, biaya tenaga kerja dan biaya listrik yang digunakan pada periode tersebut. Perhitungan biaya produksi dicantumkan pada tabel berikut.
Tabel 4. Biaya Produksi

\begin{tabular}{lcc}
\hline \multicolumn{1}{c}{ Bulan } & Bahan & Listrik \\
\hline Agustus & Rp12.484.768.198 & Rp17.174.916 \\
September & Rp12.484.768.198 & Rp17.174.916 \\
Oktober & Rp12.576.318.863 & Rp17.300.859 \\
November & Rp12.500.535.175 & Rp17.196.606 \\
Desember & Rp13.008.134.668 & Rp17.894.895 \\
Januari & Rp12.863.754.568 & Rp17.696.276 \\
Februari & Rp12.919.573.003 & Rp17.773.063 \\
Maret & Rp13.251.585.626 & Rp18.229.803 \\
April & Rp13.576.070.298 & Rp18.676.187 \\
Mei & Rp13.215.090.219 & Rp18.179.597 \\
Juni & Rp13.064.095.277 & Rp17.971.878 \\
Juli & Rp13.319.209.237 & Rp18.322.831 \\
Total & Rp160.165.314.706 & Rp220.334.549 \\
Total Keseluruhan & \multicolumn{2}{c}{ Rp160.385.649.255 } \\
\hline
\end{tabular}

Dari Tabel 4 terlihat bahwa untuk memproduksi $8700000 \mathrm{~m}$ produk 3 side seal dan pillow seal memerlukan biaya $\mathrm{Rp}$ 160.385.649.255 sehingga dapat dikatakan bahwa biaya listrik dan bahan baku untuk membuat $1 \mathrm{~m}$ produk 3 side seal dan pillow seal adalah $\mathrm{Rp} 160.385 .649 .255 / 8700000 \mathrm{~m}=\mathrm{Rp}$ 18.435 .

Dengan begitu dapat dikatakan biaya produksi untuk reguler time per $\mathrm{m}$ adalah $\mathrm{Rp} 18.435+\mathrm{Rp} 6.712=\mathrm{Rp}$ 25.147 sedangkan untuk biaya produksi dengan menggunakan over time per $\mathrm{m}$ adalah $\mathrm{Rp} 18.435+$ $\mathrm{Rp} 6.712=\mathrm{Rp} 25.147$. perhitungan biaya produksi aktual adalah sebagai berikut :

Tabel 5. Total Biaya Produksi

\begin{tabular}{|c|c|c|c|}
\hline Bulan & Biaya RT & Biaya OT & Total Biaya \\
\hline Agustus & Rp. 10.950 .468 .466 Rp. & 1.945 .812 .249 & Rp. 12.896 .280 .715 \\
\hline September & Rp. 9.954.971.333 Rp. & 3.183 .857 .516 & Rp. 13.138.828.849 \\
\hline Oktober & Rp. 10.452.719.900 Rp. & 1.044 .789 .298 & Rp. 11.497.509.198 \\
\hline November & Rp. 10.950 .468 .466 Rp. & 8.831 .433 .162 & Rp. 19.781 .901 .628 \\
\hline Desember & Rp. 8.959 .474 .200 Rp. & 701.102 .983 & Rp. 9.660 .577 .183 \\
\hline Januari & Rp. 15.430.205.566 Rp. & 3.213 .153 .965 & Rp. 18.643.359.531 \\
\hline Februari & Rp. 13.936.959.866 Rp. & 7.023 .628 .559 & Rp. 20.960 .588 .425 \\
\hline Maret & Rp. $15.430 .205 .566 \mathrm{Rp}$ & 7.370 .810 .330 & Rp. 22.801 .015 .896 \\
\hline April & Rp. 4.640 .311 .100 & - & Rp. 4.640 .311 .100 \\
\hline Mei & Rp. 15.430.205.566 Rp. & 891.517 .322 & Rp. 16.321 .722 .889 \\
\hline Juni & Rp. $14.932 .457 .000 \mathrm{Rp}$ & 6.179 .161 .583 & Rp. 21.111.618.583 \\
\hline Juli & $\begin{array}{c}\text { Rp. 15.430.205.566 Rp. } \\
\text { Jumlah }\end{array}$ & 606.046 .696 & $\begin{array}{l}\text { Rp. } 16.036 .252 .262 \\
\text { Rp. 187.489.966.259 }\end{array}$ \\
\hline
\end{tabular}

Berdasarkan asumsi biaya simpan yang dikeluarkan oleh perusahaan adalah sebesar $1 \%$ per $\mathrm{m}$ dapat dihitung dengan rumus. Biaya simpan per $\mathrm{m}$ per bulan = biaya produksi per $\mathrm{m} \times$ persentase biaya

Biaya Simpan $=\frac{R p \cdot 187 \cdot 489.966 \cdot 259}{8700000} \times 100 \%=0,0833$

3. Perencanaan produksi dengan program dinamik Perencanaan produksi ini menggunakan metode dynamic programing dengan rekrusif maju dimana perhitungannya dimulai dari tahap ke-1 bergerak 
maju hingga ke tahap ke- 12. Jangka waktu perencanaan 1 tahun dengnaperiode 1 buann, sehiingga ada 12 tahap pelaksanaan yang dimulai pada periode bulan Agustus 2017 sampaii dengan juli 2018. Jumlah produksi paling optimal akan diperoleh berdasarkan jumlah totoal biaua produksi minimum yang terdapat pada masingmasing kebijakan produksi yang disusun.

$f_{n} *(\mathrm{i})=\min \left[f_{n}\left(X_{n}, I_{n}+X_{n}-S_{n}\right)+f^{*} n-1\left(I_{n}+X_{n}-S_{n}\right)\right]$

Tahap 1. Dari jumlah pejualan dalam periode pertama adalah 678159 dengan $0 \leq I 1 \leq 1795$. Sehingga didapat hasil sebagai berikut.

$$
\begin{aligned}
& f_{1}(0) \quad=(\operatorname{Rp~} 18.435 * 678159)+((678159-607619) * \mathrm{Rp} 13.424) \\
& +(\operatorname{Rp~} 1.795 *(0+607619-678159)) \\
& =\operatorname{Rp} 13.322 .240 .694 \\
& f_{1}(6598)=(\operatorname{Rp~18.435*678159)}+((678159-607619) * \operatorname{Rp} 13.424)+
\end{aligned}
$$

(Rp 1.795*(6598+607619-678159))

e-ISSN 2657-0181

$$
\begin{aligned}
& =\operatorname{Rp} 13.587 .345 .051 \\
& f_{1}(9897)=(\operatorname{Rp~18.435*678159)}+((678159-607619) * \mathrm{Rp} 13.424) \\
& +(\operatorname{Rp~} 1.795 *(9897+607619-678159)) \\
& =\operatorname{Rp} 13.593 .267 .293 \\
& f_{1}(13196)=(\operatorname{Rp~} 18.435 * 678159)+((678159-607619) * \operatorname{Rp} 13.424) \\
& +(\operatorname{Rp} 1.795 *(13196+607619-678159)) \\
& =\mathrm{Rp} 13.599 .189 .534
\end{aligned}
$$

Dengan biaya perhitungan tersebut berulang sampai ke tahap 12 yaitu Juli 2018.

4. Rencana produksi dengan menggunakan program dinamis

Perhitungan perencanaan produksi menggunakan sistem dinamis dapat dilihat pada Tabel 6 berikut ini:

\begin{tabular}{|c|c|c|}
\hline Bulan & Biaya Produksi Aktual & Biaya Minimum \\
\hline Agustus & Rp 12.896.280.715 & Rp 13.322.240.694 \\
\hline September & Rp 13.138.828.849 & Rp 13.964.599.249 \\
\hline Oktober & Rp 11.497.509.198 & Rp 13.792.926.302 \\
\hline November & Rp 19.781.901.628 & Rp 13.347.988.872 \\
\hline Desember & Rp 9.660 .577 .183 & Rp 15.461.638.655 \\
\hline Januari & Rp 18.643.359.531 & Rp 10.497.091.846 \\
\hline Februari & Rp 20.960.588.425 & Rp 11.860.153.605 \\
\hline Maret & $\operatorname{Rp} 22.801 .015 .896$ & Rp 11.206.073.061 \\
\hline April & Rp 4.640 .311 .100 & Rp 12.219.593.469 \\
\hline Mei & Rp 16.321.722.889 & Rp 11.139.357.007 \\
\hline Juni & Rp 21.111.618.583 & Rp 11.283.668.751 \\
\hline Juli & Rp 16.036.252.262 & Rp 11.329.693.565 \\
\hline Total & Rp187.489.966.259 & Rp149.425.025.077 \\
\hline
\end{tabular}

Tabel 6. Rencana Produksi dengan program dinamis

\begin{tabular}{cccccc}
\hline Bulan & \multirow{2}{*}{ Produksi } & 0 & 6598 & 9897 & 13196 \\
\hline Agustus & 678159 & Rp13.771.130.658 & Rp14.045.220.486 & Rp14.051.343.456 & Rp14.057.466.427 \\
September & 678159 & Rp14.410.128.229 & Rp14.889.262.745 & Rp14.895.385.716 & Rp14.901.508.686 \\
Oktober & 683132 & Rp14.243.156.372 & Rp14.638.228.137 & Rp14.644.351.107 & Rp14.650.474.077 \\
November & 679015 & Rp13.797.399.047 & Rp14.074.668.010 & Rp14.080.790.981 & Rp14.086.913.951 \\
Desember & 706587 & Rp15.921.074.465 & Rp16.710.781.377 & Rp16.716.904.347 & Rp16.723.027.318 \\
Januari & 698745 & Rp11.527.047.455 & Rp10.954.852.169 & Rp10.960.975.139 & Rp10.967.098.110 \\
Februari & 701777 & Rp12.578.539.470 & Rp12.325.166.029 & Rp12.331.288.999 & Rp12.337.411.969 \\
Maret & 719811 & Rp12.173.188.911 & Rp11.679.192.985 & Rp11.685.315.955 & Rp11.691.438.925 \\
April & 737437 & Rp13.033.291.640 & Rp12.707.244.724 & Rp12.713.367.695 & Rp12.719.490.665 \\
Mei & 717829 & Rp12.112.386.160 & Rp11.611.031.573 & Rp11.617.154.543 & Rp11.623.277.513 \\
Juni & 709627 & Rp12.180.321.565 & Rp11.751.043.828 & Rp11.757.166.799 & Rp11.763.289.769 \\
Juli & 723484 & Rp12.285.852.449 & Rp11.805.491.643 & Rp11.811.614.613 & Rp11.817.737.584 \\
\hline
\end{tabular}

Setelah dilakukan perhitungan dengan menggunakan program dinamis mka dapat diketahui rencana produksi untuk setiap periode yaitu produksi dengan biaya yang minimum dan akan menghasilkan suatu solusi yang optima pada keseluruhan tahap penjadwalan.

Tabel 6. Perbandingan biaya produksi aktual dengan program dinamis
Dari tabel diatas memperlihatkan perbandingan antara biaya produksi aktual dengan biaya produksi menggunakan sistem dinamik setiap bulannya. Dari tabel tersebut juga terlihat bahwa total biaya produksi dengan menggunakan program dinamik dapat melakukan penghematan biaya produksi. . berdasarkan perhitungan diatas juga jika perusahaan menerapkan metode program dinamik, perusahaan bisa menghemat biaya produksi sebesar $\mathrm{Rp}$ 38.064.941.182 atau setara dengan 20\%. Perbedaan ini dipengaruhi oleh besarnya jumlah produksi, dimana pada perhitungan perusahaan terdapat banyak jumlah produksi lembur yang meningkatkan biaya produksi sedangkan dalam perencanaan produksi menggunakan program dinamik permintaan dapat dipenuhi dengan menggunakan overtime atau menggunakan persediaan awal, sehingga tidak terjadi peningkatan dalam biaya produksi. 


\section{SIMPULAN}

Pada perhitungan biaya produksi aktual periode juli 2017 sampai dengan agustus 2018 biaya yang dikeluarkan oleh perusahaan sebesar Rp187.489.966.259. berdasarkan dengan penerapan metode program dinamis dalam perencanaan prodksi dapat dilakukan penghematan biaya sebesar $\mathrm{Rp}$ 38.064.941.182. berdasarkan perhitungan diatas juga jika perusahaan menerapkan metode program dinamik, perusahaan bisa menghemat biaya produksi sebesar Rp 38.064.941.182 atau setara dengan 20\%. Perbedaan ini dipengaruhi oleh besarnya jumlah produksi, dimana pada perhitungan perusahaan terdapat banyak jumlah produksi lembur yang meningkatkan biaya produksi sedangkan dalam perencanaan produksi menggunakan program dinamik permintaan dapat dipenuhi dengan menggunakan overtime atau menggunakan persediaan awal, sehingga tidak terjadi peningkatan dalam biaya produksi.

\section{REFERENSI}

[1] V. Gasperz, Production Planning and Inventory Control berdasarkan pendekatan sistem terintegrasi MRP II dan JIT menuju manufacturing 21. JAKARTA: PT Gramedia Pustaka Utama. 2005.

[2] A. R. Brahmana, Poerwanto, \& T. S. Sinaga. Optimasi produksi dengan program dinamis pada pabrik fractination and refinery factory (frf) pt. xyz e-jurnal Teknik Industri Usu, 3(4), 49-54. 2013.

[3] B. H. Purnomo, Y. Wibowo, \& K. Maulidiah. Perencanaan Produksi Kerupuk Puli Dengan Metode, 9(1), 63-70. 2015.

[4] Tampubolon, F. W. C. (2009). Penerapan Dynamic Programing sebagai solusi optimal dalam penyusunan rencana produksi. Universitas Sumatra Utara.

[5] P. Delfianda, H. Komalig, T. Manurung, Optimalisasi Biaya Total Perencanaan dan Pengendalian Persediaan Menggunakan Program Dinamik (Studi Kasus: Nabila Bakery SPMA Kalasey Manado) Jurnal d'Cartesian: Jurnal Matematika dan Aplikasi, 4 (1), 1-8. 2015

[6] R. Ginting, Sistem Produksi. Yogyakarta: Graha Ilmu. 2007.

[7] F. Zulfikarijah, Operasion Research . Malang : Bayumedia Publishing. 2004.

[8] Siswanto, Operasion Research. Jakarta : Erlangga. 2007.

[9] D. M. Utama, Penentuan Lot Size Pemesanan Bahan Baku Dengan Batasan Kapasitas Gudang, Jurnal Ilmiah Teknik Industri, (15) 64-72. 2016. 